\title{
Massive haemorrhage due to colitis secondary to nonsteroidal anti-inflammatory drugs
}

\author{
E Sacanella, F Muñoz, F Cardellach, R Estruch, O Miró, A Urbano-Márquez
}

\author{
Summary \\ A case of massive haemorrhage due to \\ colitis induced by nonsteroidal anti- \\ inflammatory drugs in a 74-year-old man \\ is reported.
}

Keywords: colitis, intestinal bleeding, ketorolac, nonsteroidal anti-inflammatory drugs

The adverse effects of nonsteroidal antiinflammatory drugs (NSAIDs) such as damage to gastroduodenal mucosa or renal failure are well established., In recent years, several reports have related these drugs with the development of small bowel and colon diseases. $^{3-7}$

A case of massive lower intestinal bleeding due to NSAID intake is reported in a patient who also had an aneurysm of the abdominal aorta.

\section{Case report}

A 74-year-old man was admitted to the hospital with haematochezia. Five months previously, the patient had complained of severe and progressive back pain and different NSAIDs (diclofenac, naproxen, aceclofenac) were alternatively prescribed. Four days before admission the patient presented with severe lower intestinal bleeding and visited another hospital. No previous episodes of gastrointestinal bleeding or other digestive symptoms were reported, but the NSAIDs were discontinued. A rectosigmoidoscopy was performed. No lesions were observed, although blood was present in the colon. Bleeding stopped spontaneously and the patient was transferred to our hospital.

Physicial examination disclosed mild skin pallor and spontaneous and persistent bilateral lumbar pain which increased with mobilisation of the spine. The respiratory and cardiocirculatory systems were normal. A tender pulsatile mass of $6 \mathrm{~cm}$ was found in the abdomen. Blood analysis revealed an erythrocyte sedimentation rate of $54 \mathrm{~mm} / \mathrm{h}$, haematocrit $0.33 \mathrm{l} / \mathrm{l}$, haemoglobin $105 \mathrm{~g} / \mathrm{l}$ and mean corpuscular volume $93 \mathrm{fl}$. An abdominal X-ray (figure) disclosed a calcified aortic aneurysm and generalised osteoporosis.

Two days after admission, ketorolac $(30 \mathrm{mg} /$ day) was started because of severe back pain. Forty-eight hours later life-threatening lower intestinal bleeding recurred; the patient was

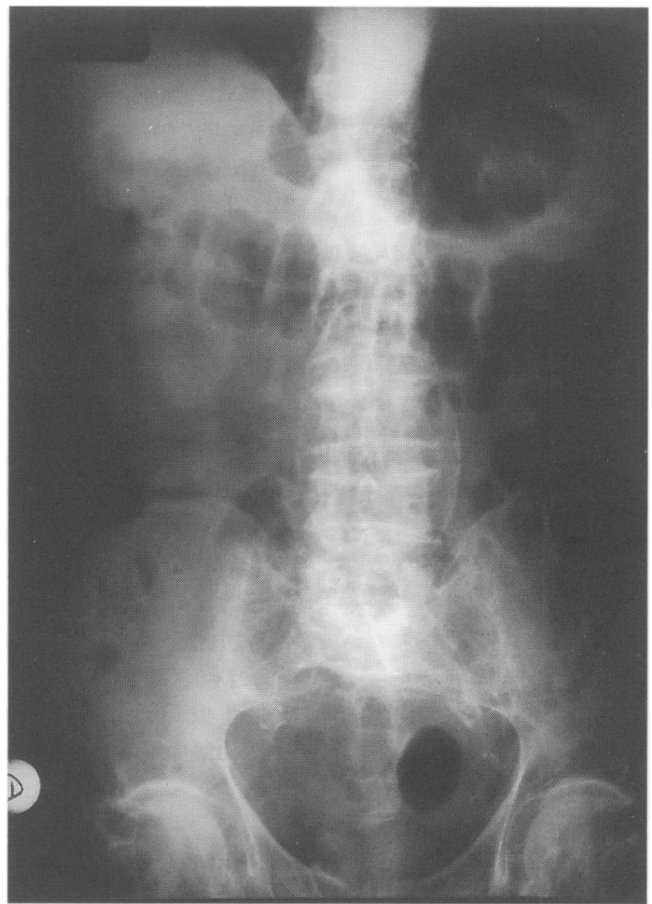

Figure Abdominal X-ray

hypotensive, diaphoretic and pale. Although plasma expanders and packed red cells were infused the patient remained hypotensive because of bleeding recurrence. Rupture of the aortic aneurysm into the bowel was suspected and emergency laparotomy was performed. An unruptured aortic aneurysm was found and replaced with a prosthesis. Both mesenteric arteries were macroscopically normal. During surgery, strong life-support management allowed normalisation of the arterial pressure. Three days later, colonoscopy disclosed large bloody ulcerations widely distributed in the colon, although the rectal mucosa was normal. Histologic study of several specimens revealed mononuclear infiltrate in the mucosa with no evidence of malignancy or inflammatory bowel disease. Non-specific colitis was diagnosed. The possible association between pancolitis and NSAID administration led to discontinuation of ketorolac. Bleeding stopped 24 hours later. Another colonoscopy performed 14 days later showed mild improvement of the ulcerations. Two months after discharge the patient remains asymptomatic. 


\begin{tabular}{|l|}
\hline NSAID-induced colitis: clinical \\
settings \\
\hline - de novo colitis \\
- proctitis after rectal administration of NSAID \\
- hypersensitivity colitis in atopic patients \\
disease
\end{tabular}

Box 1

\section{Discussion}

The clinical settings in which NSAID-induced colitis may present are shown in box $1 .^{4,8}$ In our patient the diagnosis was supported by the chronological relationship between the administration of the drug and the development of gastrointestinal bleeding, with recurrence after re-exposure to the drug. Moreover, the clinical and histologic improvement when ketorolac was removed confirmed the diagnosis. The absence of clinical or histological data rule out other causes of ulcerative pancolitis such as inflammatory bowel disease or ischaemic colitis. To our knowledge, ketorolac has not previously been associated with the development of colitis, probably because of its relatively recent introduction in clinical practice.

Colitis induced by NSAIDs is frequently observed in elderly patients and symptoms begin several months after drug intake. Most patients have diarrhoea with occult or obvious

1 Soll AH. Nonsteroidal anti-inflammatory drugs and peptic ulcer disease. Ann Intern Med 1991; 114: 307-19.

2 Flower RJ, Moncada S, Vane JR. Drug therapy of inflammation. In: Goodman, Gilman, eds. The pharmacological basis of therapeutics. London: Macmillan, 1985 pp 674-716.

3 Aabakken L, Osnes M. Non-steroidal anti-inflammatory drug-induced disease in the distal ileum and large bowel. Scand 7 Gastroenterol 1989; 24 (suppl 163): 48-55.

4 Gibson GR, Whitacre EB, Ricotti CA. Colitis induced by nonsteroidal anti-inflammatory drugs. Report of four cases and review of the literature. Arch Intern Med 1992; 152 625-32.

5 Tanner AR, Raghunath AS. Colonic inflammation and nonsteroidal anti-inflammatory drug administration: an assessment of the frequency of the problem. Digestion 1988; 41: $116-120$.

6 Allison MC, Howatson AG, Torrance CJ, Lee FD, Russell RI. Gastrointestinal damage associated with the use of nonsteroidal anti-inflammatory drugs. $N$ Engl f Med 1992 327: $749-54$.

\section{Summary/learning points}

- NSAIDs may have deleterious effects on upper and lower gastrointestinal tract

- in every patient who consults for digestive haemorrhage a detailed history of drugs consumed must be performed

- inflammatory bowel disease may be exacerbated by NSAIDs

- NSAIDs may induce colitis similar to inflammatory bowel disease

\section{Box 2}

blood, although weight loss, abdominal pain or fever may also be present. ${ }^{4}$ NSAID-induced colitis may affect any area of the colon and perforation and haemorrhage are the most severe complications. ${ }^{3,4,9-11}$ On review of the literature, no other cases presenting as massive haemorrhage and hypovolemic shock were found.

The mechanism of NSAID-induced colitis may be related to the inhibition of intestinal prostaglandin synthesis. ${ }^{3,4}$ Diagnosis requires exclusion of other causes, a relationship between the length of drug administration and the onset of symptoms, and resolution after withdrawal of the drug. ${ }^{4}$ Discontinuation of the drug and supportive management is the basic treatment, although surgery may be required on the presentation of severe complications. Re-exposure to NSAIDs must be avoided due to the high risk of relapse.

7 Bjarnason I, Zanelli G, Smith $\mathrm{T}$, et al. Nonsteroida anti-inflammatory drug-induced intestinal inflammation in humans. Gastroenterology 1987; 93: 480-3.

8 Kaufmann HJ, Taubin HL. Nonsteroidal antiinflammatory drug activate quiescent inflammatory bowe disease. Ann Intern Med 1987; 107: 513-6.

9 Langman MJS, Morgan L, Warrall A. Use of antiinflammatory drugs by patients admitted with small or large bowel perforations and hemorrhage. BMF 1985; 290: 347-9.

10 Saverymuttu SH, Thomas A, Grundy A, Maxwell JD. Ileal strictising after long-term indomethacin (therapy) treatment. Postgrad Med F 1986; 62: 967-8.

11 Bjarnason I, Price AZ, Zanelli G, et al. Clinicopathologica features of nonsteroidal anti-inflammatory drug-induced small intestinal strictures. Gastroenterology 1988; 94: 1070-4. 